\title{
CARACTERÍSTICAS ARQUITETÔNICAS E O DECAIMENTO SONORO DE SALAS ACOPLADAS: UMA REVISÃO DA LITERATURA
}

\section{ARCHITECTURAL FEATURES AND THE SOUND DECAY OF COUPLED ROOMS: A LITERATURE REVIEW}

\author{
Alexandre Maiorino 1 \\ Programa de Pós-Graduação em Arquitetura, Tecnologia e Cidade, Universidade Estadual de Campinas, Campinas, SP, Brasil, \\ maiorino.alexandre@gmail.com \\ Stelamaris Rolla Bertolli 2 \\ Faculdade de Engenharia Civil, Arquitetura e Urbanismo, Campinas, SP, Brasil, rolla@ @ec.unicamp.br
}

\section{Resumo}

Nas últimas décadas, o crescente número de salas de concerto construídas com variabilidade acústica impulsionou o estudo acústico de salas acopladas. Esta variabilidade tem sido feita de diversas formas, sendo uma delas o acoplamento de câmaras reverberantes na sala principal de espetáculos. Salas acopladas propiciam um decaimento de energia sonora diferenciado, a energia decai de forma não exponencial. As características arquitetônicas do espaço têm influência direta na formação do decaimento não exponencial de energia sonora. Os objetivos deste trabalho são identificar e analisar, na literatura, as características e parâmetros arquitetônicos propostos ao longo dos anos que influenciam a formação de curvas de decaimento de energia não exponencial em salas acopladas. O trabalho foi desenvolvido empregando a Revisão Sistemática da Literatura (RSL). Os resultados mostraram que a combinação de três características arquitetônicas são as responsáveis pela formação de curvas de decaimento não exponencial de energia. A relação entre estas características foi sistematizada em três parâmetros arquitetônicos, a saber: a área de acoplamento, a razão de volumes, e a razão de absorção. A RSL permitiu avaliar o estado da arte sobre o assunto, identificar o período de maior interesse nas pesquisas sobre salas acopladas e observar a aplicação da teoria de salas acopladas para compreensão da acústica de igrejas e catedrais. Foi possível encontrar lacunas em pesquisas relacionadas à psicoacústica de salas acopladas e dos parâmetros arquitetônicos razão de volumes e razão de absorção além de identificar a necessidade em pesquisas de acoplamento de caixa cênica em teatros. Os resultados deste trabalho fornecem subsídios para serem empregados na elaboração de projetos acústicos de ambientes que se utilizam de salas acopladas para sua adequação acústica.

Palavras-chave: Salas Acopladas. Decaimento de Energia Sonora. Acústica Arquitetônica. Parâmetros Arquitetônicos. Revisão Sistemática da Literatura

\begin{abstract}
In the past decades, the increasing number of concert halls with acoustic variability promoted the study of coupled room acoustics. The acoustic variability can be performed in many ways such as coupling a reverberant room to the main theater. Coupled rooms have a unique sound energy decay. Architectural features have a direct influence in the non-exponential sound decay. This study aims to identify in the literature and analyze the architectural features and architectural parameters proposed along the years that influence the formation of non-exponential sound decays in coupled rooms. This study was made through a Systematic Literature Review (SLR). Results showed that the combination of three architectural features is responsible for the non-exponential sound decay. The relations between those features resulted in three architectural parameters: Aperture Coupling Area, Volume Rate, and Absorption Rate. Results showed that the SLR was able to present the state of the art of the researched subject and was able to identify the period of most interest in coupled room researches. It also allowed understanding how coupled room theories have been contributing to the understanding of church acoustics and to observe research gaps regarding coupled room psychoacoustics and the architectural parameters Volume Rate and Absorption Rate. It also identified the need for future research on stagehouse coupling in theaters. Results from this work will subsidize future acoustics projects involving coupled room acoustics.
\end{abstract}

Keywords: Coupled Rooms. Sound Energy Decay. Architectural Acoustics. Architectural Parameters. Systematic Literature Review

\footnotetext{
How to cite this article:

MAIORINO, Alexandre Virginelli; BERTOLI, Stelamaris Rolla. Características arquitetônicas e o decaimento sonoro de salas acopladas: uma revisão da literatura. PARC Pesquisa em Arquitetura e Construção, Campinas, SP, v. 8, n. 3, p. 194-204, set. 2017. ISSN 1980-6809. Disponível em: <https://periodicos.sbu.unicamp.br/ojs/index.php/parc/article/view/8650222>. Acesso em: 20 jan. 2018.
}

doi:http://dx.doi.org/10.20396/parc.v8i3.8650222. 


\section{Introdução}

O trabalho pioneiro de Sabine (1922) marca o início do estudo de acústica de salas ao propor um modelo matemático para predizer o tempo de decaimento sonoro dentro de uma sala. Este modelo leva em consideração o volume da sala e as áreas de superfícies sujeitas à incidência sonora proveniente de uma fonte. A importância da escolha dos materiais a serem aplicados nas superfícies decorre da sua capacidade de absorção ou reflexão sonora e da sua influência no decaimento de energia sonora do ambiente. $\mathrm{O}$ decaimento sonoro resultante do modelo de Sabine (1922) é exponencial e quando é representado por uma escala logarítmica como o nível de pressão sonora em função de uma escala linear como o tempo, o decaimento sonoro se torna uma reta. Portanto, um decaimento sonoro exponencial é aquele em que o nível de pressão sonora decai linearmente em função do tempo.

Eyring (1931) é um dos precursores no estudo do decaimento sonoro de salas acopladas e foi um dos primeiros a mostrar que determinadas características arquitetônicas eram responsáveis pela produção de decaimentos de energia sonora não exponencial, também conhecido como duplo decaimento. Um decaimento sonoro não exponencial é aquele em que o nível de pressão sonora não decai linearmente em função do tempo. O estudo de salas acusticamente acopladas ganhou destaque a partir da segunda metade da década de 1990 quando apareceram as primeiras salas de concerto com variação acústica por meio do acoplamento de câmaras reverberantes. A Artec Consultants, empresa de consultoria de Nova Iorque, EUA, por influência de seu proprietário e consultor acústico Russel Johnson, foi uma das pioneiras neste tipo de variabilidade acústica. No site da empresa é possível verificar as datas de inauguração de diversas salas de concerto com variabilidade acústica obtida por acoplamento de câmaras reverberantes (ARTEC, 2017). O grande interesse dos projetistas e consultores acústicos neste tipo de fenômeno apoia-se na premissa de que o duplo decaimento de energia sonora possa proporcionar tanto a sensação de clareza como de reverberância, consideradas como antagônicas dentro da acústica de salas (ERMANN; JOHNSON, 2005). O duplo decaimento desejado para salas de concerto é aquele onde o decaimento de energia inicial é mais rápido que o decaimento de energia final da curva (BRADLEY; WANG, 2005).

Ao longo dos anos, observou-se que o duplo decaimento de energia sonora acontece também em outros ambientes como grandes igrejas e catedrais, onde a própria arquitetura do local como capelas, altares colaterais e corredores laterais formam ambientes menores acoplados à nave principal. Estes ambientes são conectados por $\operatorname{arcos}$ e aberturas, formando uma rede intrincada de ambientes. Neles, se observa também um outro tipo de curva com duplo decaimento, onde o decaimento de energia inicial é mais longo que o decaimento final da energia sonora (ANDERSON; BRATOS-ANDERSON, 2000; MARTELLOTTA, 2009, 2016).

O objetivo deste trabalho é identificar na literatura algumas características arquitetônicas em espaços acoplados e analisar os parâmetros arquitetônicos propostos ao longo dos anos que são responsáveis pelo duplo decaimento de energia sonora. Como metodologia, utilizou-se uma Revisão Sistemática da Literatura (RSL) realizada em três etapas: Planejamento, Condução da Revisão e Análise de dados. Os resultados desse estudo permitiram compreender a relação entre parâmetros e características arquitetônicas que propiciam a formação de um decaimento de energia sonora não exponencial entre duas ou mais salas acopladas acusticamente. A importância desse estudo está na aplicação dos resultados como subsídios para a adequação acústica de projetos de teatros e salas de concerto com variabilidade acústica ou outros ambientes que necessitam empregar acoplamento de salas.

\section{Revisão Sistemática da Literatura}

A Revisão Sistemática da Literatura pode ser considerada uma metodologia de trabalho que visa criar um protocolo de busca de literatura de maneira criteriosa, para que possa responder a uma determinada questão. Esta busca deve ser sistemática, imparcial e deve ser documentada ao longo do processo (KITCHENHAM, 2004). A Revisão Sistemática da Literatura para o desenvolvimento deste trabalho foi conduzida em três etapas: Planejamento, Condução da Revisão e Análise de Dados.

\section{Planejamento da Revisão}

$\mathrm{Na}$ fase de Planejamento da Revisão foi escrito um Protocolo de Revisão Sistemática da Literatura onde se buscou delimitar o escopo da pesquisa, os critérios de definição de buscas, bem como o critério de seleção, inclusão, exclusão e aprovação dos artigos. Como escopo, definiu-se a seguinte questão: "Quais são as características arquitetônicas dos ambientes e como suas inter-relações propiciam a formação de uma curva com decaimento de energia não exponencial para esse ambiente?".

Para responder a esta questão, inicialmente foi realizada uma busca na internet através do site de busca google scholar sem qualquer sistematização, apenas como controle, utilizando palavras-chave como "double slope decay", "coupled room" e "architectural parameters". Os artigos escolhidos para a leitura inicial deveriam estar 
publicados em congressos nacionais ou internacionais de acústica ou publicados em periódicos reconhecidamente tradicionais dentro da área. Da leitura dos artigos encontrados e pertinentes ao escopo da pesquisa foram analisadas e escolhidas as palavras que poderiam ser utilizadas como palavras-chave da busca da revisão sistemática. As palavras-chave foram separadas em três grupos: um que propiciasse encontrar artigos sobre salas acopladas e decaimento não exponencial de energia, outro que abordasse os parâmetros ou características arquitetônicas que influenciam no decaimento da energia sonora e por último foi escolhida a palavra-chave "acoustics" para delimitação da busca dentro da área de acústica. Na busca, deveriam ser encontrados artigos que apresentassem pelo menos uma palavra-chave de cada um dos grupos. Assim, na criação do string de busca, dentro de cada um dos grupos foi utilizado o operador booleano OR entre as palavras-chave daquele grupo. A combinação dos grupos de palavras-chave foi feita com o operador booleano AND. Os strings básicos de busca podem ser vistos no Quadro 1.

As bases de dados escolhidas para a busca da revisão sistemática da literatura foram SCOPUS, WEB OF SCIENCE, COMPENDEX e SCIENCE DIRECT. Estas bases foram escolhidas por apresentarem a maior parte dos periódicos de acústica dentro da área de engenharia e arquitetura. Todas as bases escolhidas estão disponíveis para busca online através da assinatura existente em universidades. Para as bases escolhidas foram criados strings de busca adequados a cada uma das particularidades das bases pesquisadas seguindo os strings básicos do Quadro 1.

Os campos pesquisados nas bases de dados foram "Resumo", "Título" e "Palavras-chave". Pequenas alterações foram feitas para adequação da busca ao sistema de cada uma das bases de dados de acordo com as instruções por elas fornecidas. Na base "Web of Science" foi necessário escolher "Todas as bases de dados" para a pesquisa. Nas bases "Science Direct" e "Compendex" foi utilizada a ferramenta Expert Search por ser esta a que permite a pesquisa por strings de busca. O Quadro 2 mostra cada um dos strings adaptados de acordo com as particularidades de cada uma das bases de dados.

Quadro 1: Esquema da combinação entre os três grupos selecionados de palavraschaves

\begin{tabular}{|c|c|c|c|c|}
\hline Grupo 1 & \multirow{8}{*}{ AND } & Grupo 2 & \multirow{8}{*}{ AND } & Grupo 3 \\
\hline $\begin{array}{l}\text { Non-single-exponential } \\
\text { Sound Decay OR }\end{array}$ & & \multirow{3}{*}{$\begin{array}{c}\text { Architectural } \\
\text { Parameters } \\
\text { OR }\end{array}$} & & \multirow{7}{*}{ Acoustics } \\
\hline Coupled Room OR & & & & \\
\hline Coupled Space OR & & & & \\
\hline $\begin{array}{c}\text { Non-exponential Sound } \\
\text { Decay OR }\end{array}$ & & \multirow{2}{*}{$\begin{array}{c}\text { Aperture Size } \\
\text { OR }\end{array}$} & & \\
\hline Coupled Volume OR & & & & \\
\hline $\begin{array}{c}\text { Double Slope Sound } \\
\text { Decay OR } \\
\end{array}$ & & \multirow{2}{*}{$\begin{array}{c}\text { Sound } \\
\text { Absorption } \\
\text { OR }\end{array}$} & & \\
\hline Coupling Effect OR & & & & \\
\hline
\end{tabular}

Os parâmetros KY, TITLE-ABS-KEY, TAK e TS restringem as buscas para os campos Abstract, Title $e$ Keyword nas bases de dados Compendex, Scopus, Science Direct e Web of Science respectivamente. As buscas foram feitas em artigos escritos apenas na língua inglesa, por ser o idioma mais utilizado dentro do meio acadêmico na atualidade. Os dados obtidos nas buscas foram exportados para o programa Zotero que permite a organização e gerenciamento dos artigos encontrados.

Quadro 2: Strings de busca para cada uma das quatro bases de dados.

\begin{tabular}{|c|c|}
\hline Base & String \\
\hline Compendex & $\begin{array}{c}\text { (\{Non-single-exponential sound decay\} OR \{Coupled room\} OR \{Coupled Space }\} \text { OR \{non-exponential sound decay\} OR \{coupled } \\
\text { volume } \text { OR \{Double Slope Sound Decay\} OR \{coupling effect\} wn KY) AND (acoustics wn KY) AND (\{Architectural Parameters }\} \text { OR } \\
\{\text { Aperture Size } O R \text { OSound Absorption\} wn KY) }\end{array}$ \\
\hline Scopus & $\begin{array}{l}\text { TITLE-ABS-KEY ( "acoustics" ) AND TITLE-ABS-KEY ( "Non-single-exponential sound decay" OR "Coupled room" OR "Coupled } \\
\text { Space" OR "non-exponential sound decay" OR "coupled volume" OR "Double Slope Sound Decay" OR "coupling } \\
\text { effect" ) AND TITLE-ABS-KEY ( "Architectural Parameters" OR "Aperture Size" OR "Sound Absorption" ) }\end{array}$ \\
\hline Science Direct & 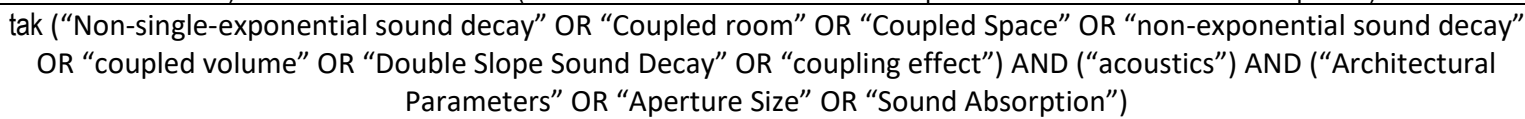 \\
\hline Web of Science & $\begin{array}{l}\text { TS=((“Non-single-exponential sound decay" OR "Coupled room" OR "Coupled Space" OR "non-exponential sound decay" OR } \\
\text { "coupled volume" OR "Double Slope Sound Decay" OR "coupling effect”) AND (acoustics) AND ("Architectural Parameters" OR } \\
\text { "Aperture Size" OR "Sound Absorption")) }\end{array}$ \\
\hline
\end{tabular}

Fonte: Os autores

Para a seleção dos artigos foram estabelecidos critérios de inclusão e exclusão, e após triagem, os artigos passaram por um critério de aprovação para serem avaliados na Revisão Sistemática da Literatura (RSL). Inicialmente foi feita a leitura do título e palavras-chave, em seguida a leitura dos abstracts e por último a leitura completa dos artigos. Os critérios estabelecidos após seleção dos artigos para que pudessem ser incluídos e avaliados foram: 
(a) $\mathrm{O}$ artigo deve incluir em sua proposta a análise de um parâmetro ou característica arquitetônica que influencie o duplo decaimento de energia sonora;

(b) $\mathrm{O}$ artigo pode descrever um método de cálculo, ou um experimento de medição, ou uma simulação ou uma comparação entre métodos em que um parâmetro ou uma característica arquitetônica sejam utilizados como uma variável.

Os critérios estabelecidos para a exclusão dos artigos foram:

(a) Artigos duplicados que aparecem em mais de uma base; (b) Trabalhos em que o texto completo não esteja disponível online; (c) A partir da leitura do título, o artigo não apresenta aderência ao escopo; (d) A partir da leitura do abstract, o artigo não apresenta aderência ao escopo; (e) A partir da leitura do artigo, não há aderência ao escopo.

O critério de aprovação estabelecido, para que um determinado artigo fizesse parte da revisão sistemática da literatura, seria em decorrência de apresentar pelo menos um dos critérios de inclusão e nenhum critério de exclusão. Convém ressaltar que após a leitura dos artigos aprovados, suas referências bibliográficas foram consultadas. Caso houvesse um artigo citado de relevância ao escopo e que se adequasse aos critérios de inclusão, exclusão e aprovação, este poderia ser incluído.

Nessa etapa de investigação, as seguintes informações dos artigos escolhidos foram obtidas: Título, nome dos autores, ano de publicação, nome do periódico ou congresso de publicação, parâmetros ou características arquitetônicas estudadas, método empregado na pesquisa, pequeno resumo e conclusões sintetizadas.

\section{Condução da Revisão}

As informações coletadas nesta etapa, denominada "Condução da Revisão", teve como referência o mês de Julho de 2017. Os strings de busca foram aplicados em cada uma das bases de dados selecionadas. O resultado obtido foi exportado no formato BibTex para o programa Zotero, onde foi criada uma nova coleção para cada base de dados, bem como para cada uma das etapas de seleção dos artigos. Desta maneira, cada etapa pôde ser analisada em detalhes. Após a eliminação dos artigos duplicados, a lista de artigos restantes foi transferida para uma planilha de dados, utilizada como formulário de condução. Cada um dos artigos foi numerado e colocado em ordem alfabética por título. Foram incluídos os dados dos nomes dos autores e ano de publicação. Em seguida, três colunas foram inseridas para preenchimento, sendo "Inclusão", "Exclusão" e "Status".

$\mathrm{O}$ preenchimento foi feito durante $\mathrm{o}$ processo de avaliação da aderência de cada artigo ao escopo com as letras equivalentes aos critérios de inclusão ou exclusão. O Status do artigo indicou se ele foi aprovado de acordo com o critério de aprovação. Em cada uma das etapas foi contabilizado o número de artigos incluídos.

Após atingir o número final de artigos selecionados para revisão, foram incluídas na tabela de condução da revisão, colunas referentes aos parâmetros ou características arquitetônicas encontradas e o tipo de método da pesquisa, para que também pudessem ser contabilizados.

\section{Resultados e Análise}

Após a etapa de condução da revisão sistemática da literatura foram selecionados 102 artigos considerando as quatro bases de dados pesquisadas, sendo 10 artigos na base Compendex, 60 artigos na base Science Direct, 24 artigos na base Scopus e 8 artigos na base Web of Science. Após a exclusão dos artigos em duplicidade, restaram 84 artigos. Com a leitura dos títulos e exclusão dos artigos que não apresentavam aderência ao escopo, restaram 28 artigos. Após a leitura dos resumos e exclusão dos não aderentes restaram 21 artigos que foram lidos por completo, resultando 17 artigos selecionados. Com a leitura e análise das referências bibliográficas dos artigos selecionados, foram incluídos mais quatro artigos de relevância, que atenderam ao critério de aprovação do Protocolo de Revisão e que não apareceram na busca das bases de dados. Estes quatro artigos incluídos, foram encontrados diretamente no site dos periódicos referenciados ou encontrados nos Anais do congresso tal como listados na referência bibliográfica dos artigos analisados. No total, foram selecionados 21 artigos para a Revisão Sistemática da Literatura (RSL). Dos artigos selecionados, 19 foram publicados em periódicos e dois artigos em congressos. O gráfico da Figura 1 mostra a distribuição dos artigos selecionados em relação aos periódicos e congressos a que pertencem.

Os três periódicos com maior número de artigos publicados são respectivamente: Journal of the Acoustical Society of America, Building Acoustics e Journal of Sound and Vibration. O gráfico da Figura 2 mostra a distribuição dos artigos em função do ano de publicação.

Houve um maior interesse pelo assunto abordado nesta revisão a partir do ano 2000 até os dias atuais. Isto se deve provavelmente ao fato de que a partir da década de 90, foram inauguradas várias salas de concerto com variabilidade acústica promovida por câmaras reverberantes (ARTEC, 2017). 
Figura 1: Distribuição dos artigos aderentes ao escopo em função dos periódicos e congressos

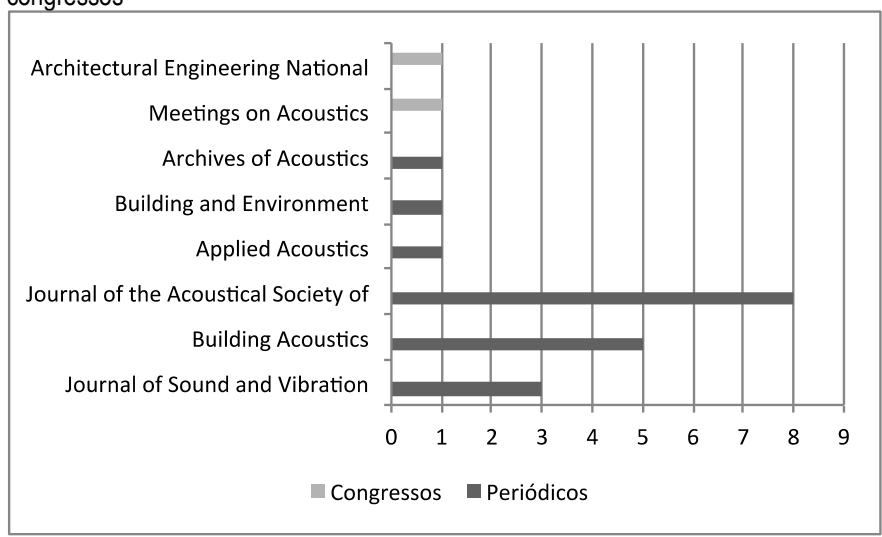

Fonte: Os autores

A empresa Artec Consultants, de Nova Iorque, foi pioneira neste tipo de projeto. O consultor acústico Russell Johnson, chegou a publicar em 1995 um artigo comentando sobre a variabilidade acústica obtidas por meio de salas acopladas, afirmando que este seria "o grande passo para a sala do futuro" (JOHNSON; KAHLE; ESSERT, 1995).

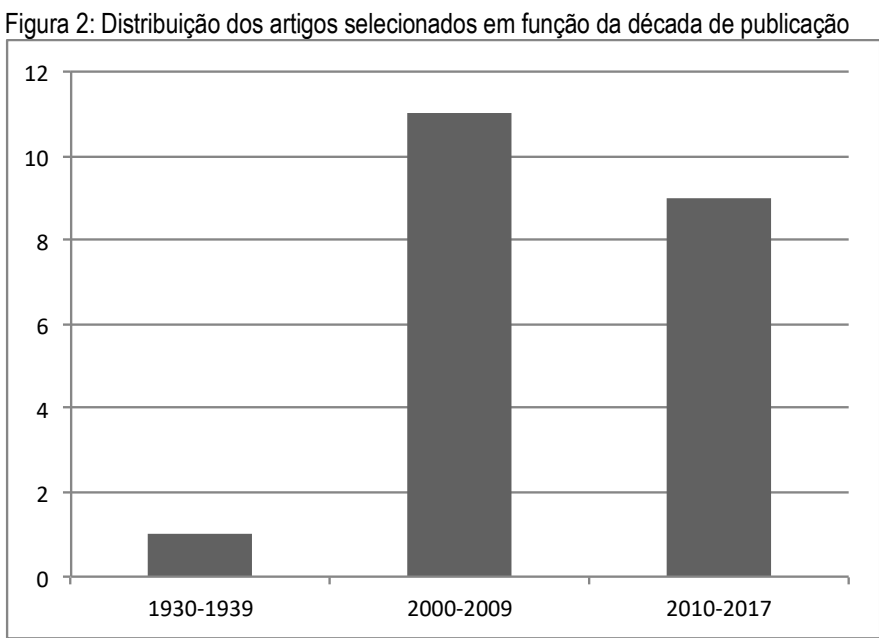

Fonte: Os autores

De 1989 a 2001, pelo menos quatro importantes salas de concerto ou teatros de múltiplo uso com variabilidade acústica promovida por acoplamento de câmaras reverberantes foram inauguradas. São elas: o McDermott Concert Hall em Dallas, o Symphony Hall em Birmingham, o Culture and Congress Center Concert Hall em Lucerne, e o Verizon Hall na Philadelphia (ARTEC, 2017). O assunto ainda é de grande interesse na área de acústica de salas e o número de projetos de salas e teatros com variabilidade acústica é crescente.

Dentre as características arquitetônicas estudadas que propiciam decaimento não exponencial em salas acopladas está a variação da área de acoplamento, sendo a característica com maior número de estudos. A relação entre volumes e a relação de absorção entre as salas são as características arquitetônicas com menor número de estudo, sendo uma boa temática para novas pesquisas, conforme pode ser visto no gráfico da Figura 3.

Figura 3: Quantidade de artigos que fazem referência a uma característica arquitetônica que propicia o decaimento de energia sonora não exponencial em salas acopladas

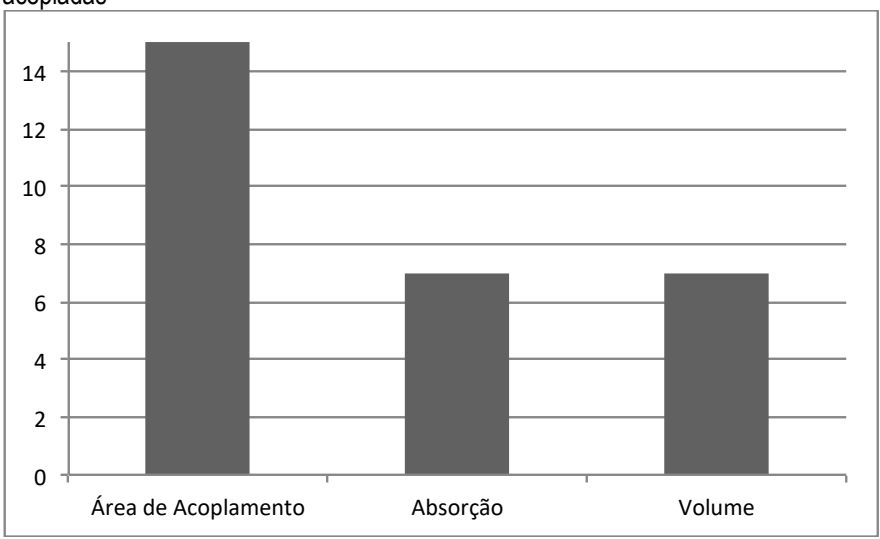

Fonte: Os autores

A catalogação dos 21 artigos incluídos na Revisão Sistemática da Literatura pode ser vista na Quadro 3.

As metodologias empregadas nos trabalhos podem ser vistas no gráfico da Figura 4. Das metodologias utilizadas destaca-se a avaliação subjetiva como um método a ser explorado em novos estudos.

Figura 4: Métodos utilizados nas pesquisas

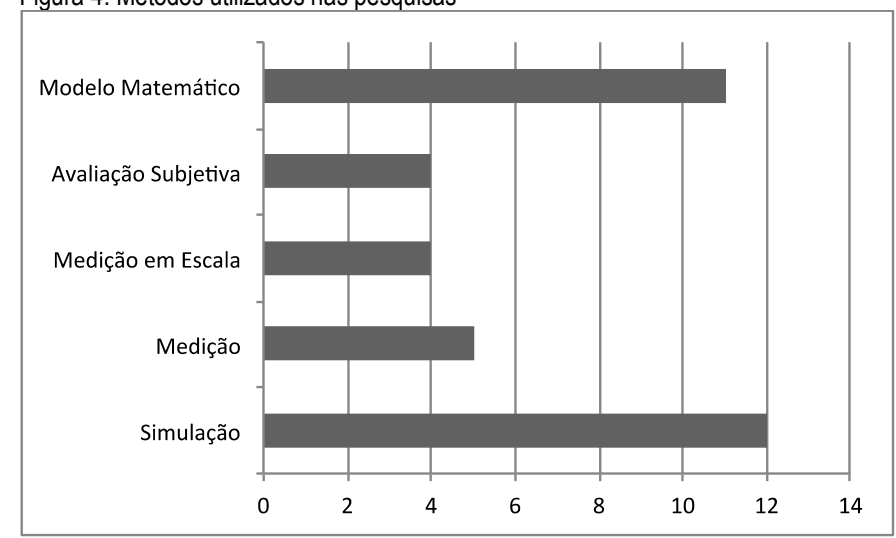

Fonte: Os autores

\section{Influência da arquitetura no decaimento sonoro de salas acopladas}

Um dos primeiros estudos sobre acústica de salas acopladas foi o de Eyring (1931). Ele propôs as relações matemáticas de troca de energia sonora entre salas acopladas através de uma determinada área de abertura e mostrou os tipos de decaimento de energia sonora em função das posições entre fonte sonora e receptor. Para que aconteça o duplo decaimento de energia é necessário que as salas acopladas tenham tempos de reverberação 
Quadro 3: Dados dos artigos aderentes ao escopo)

\begin{tabular}{|c|c|c|c|c|}
\hline Autor & Ano & Título & $\begin{array}{l}\text { Parâmetros } \\
\text { Arquitetônicos }\end{array}$ & Método \\
\hline Eyring & 1931 & Reverberation time measurements in coupled rooms & $\begin{array}{l}\text { Área de Acoplamento, } \\
\text { Razão de Absorção, } \\
\text { Razão de Volumes }\end{array}$ & Modelo Matemático/Estatístico \\
\hline $\begin{array}{l}\text { Anderson e Bratos- } \\
\text { Anderson }\end{array}$ & 2000 & $\begin{array}{l}\text { Acoustic Coupling Effects in St Paul's Cathedral, } \\
\text { London }\end{array}$ & Razão de Volumes & Medição, Modelo Matemático/Estatístico \\
\hline Ermann & 2005 & $\begin{array}{l}\text { Coupled Volumes: Aperture Size and the Double- } \\
\text { Sloped Decay of Concert Halls }\end{array}$ & Área de Acoplamento & $\begin{array}{c}\text { Medição em Escala, Modelo } \\
\text { Matemático/Estatístico, Simulação com } \\
\text { traçado de raios } \\
\end{array}$ \\
\hline Ermann & 2005 & $\begin{array}{l}\text { Coupled Volumes: Secondary Room Reverberance } \\
\text { and the Double-Sloped Decay of Concert Halls }\end{array}$ & Razão de Absorção & $\begin{array}{l}\text { Modelo Matemático/Estatístico, } \\
\text { Simulação com traçado de raios }\end{array}$ \\
\hline Ermann e Johnson & 2005 & $\begin{array}{l}\text { Exposure and Materiality of the Secondary Room and } \\
\text { Its Impact on the Impulse Response of Coupled- } \\
\text { Volume Concert Halls }\end{array}$ & $\begin{array}{l}\text { Área de Acoplamento, } \\
\text { Razão de Absorção }\end{array}$ & $\begin{array}{l}\text { Modelo Matemático/Estatístico, } \\
\text { Simulação com traçado de raios }\end{array}$ \\
\hline Bradley e Wang & 2005 & $\begin{array}{l}\text { The Effects of Simple Coupled Volume Geometry on } \\
\text { the Objective and Subjective Results from } \\
\text { Nonexponential Decay }\end{array}$ & $\begin{array}{l}\text { Área de Acoplamento, } \\
\text { Razão de Absorção, } \\
\text { Razão de Volumes }\end{array}$ & $\begin{array}{l}\text { Simulação com traçado de raios, } \\
\text { Análise Subjetiva }\end{array}$ \\
\hline Bradley e Wang & 2006 & Room Acoustics in Coupled Volume Spaces & $\begin{array}{l}\text { Área de Acoplamento, } \\
\text { Razão de Absorção }\end{array}$ & Simulação com traçado de raios \\
\hline Bradley e Wang & 2007 & $\begin{array}{l}\text { Comparison of Measured and Computer-Modeled } \\
\text { Objective Parameters for an Existing Coupled Volume } \\
\text { Concert Hall }\end{array}$ & Área de Acoplamento & $\begin{array}{c}\text { Medição, Simulação com traçado de } \\
\text { raios }\end{array}$ \\
\hline Ermann & 2007 & $\begin{array}{l}\text { Double Sloped Decay: Subjective Listening Test to } \\
\text { Determine Perceptibility and Preference }\end{array}$ & Área de Acoplamento & $\begin{array}{c}\text { Simulação com traçado de raios, } \\
\text { Avaliação Subjetiva }\end{array}$ \\
\hline Bradley e Wang & 2009 & $\begin{array}{l}\text { Quantifying the Double Slope Effect in Coupled } \\
\text { Volume Room Systems }\end{array}$ & Área de Acoplamento & Simulação com traçado de raios \\
\hline Martellotta & 2009 & $\begin{array}{l}\text { Identifying acoustical coupling by measurements and } \\
\text { prediction-models for St. Peter's Basilica in Rome }\end{array}$ & Razão de Volumes & $\begin{array}{l}\text { Modelo Matemático/Estatístico, } \\
\text { Simulação com traçado de raios }\end{array}$ \\
\hline Meissner & 2009 & $\begin{array}{l}\text { Computer modeling of coupled spaces: Variations of } \\
\text { eigenmodes frequency due to a change in coupling } \\
\text { area }\end{array}$ & Área de Acoplamento & Modelo Matemático/Estatístico \\
\hline Bradley e Wang & 2010 & $\begin{array}{l}\text { Optimum Absorption and Aperture Parameters for } \\
\text { Realistic Coupled Volume Spaces Determined from } \\
\text { Computational Analysis and Subjective Testing Results }\end{array}$ & $\begin{array}{l}\text { Área de Acoplamento, } \\
\text { Razão de Absorção, } \\
\text { Razão de Volumes }\end{array}$ & Simulação com traçado de raios \\
\hline $\mathrm{Pu}$, et al. & 2011 & $\begin{array}{l}\text { Different sound decay patterns and energy feedback in } \\
\text { coupled volumes }\end{array}$ & Razão de Absorção & $\begin{array}{c}\text { Medição em escala, Modelo } \\
\text { Matemático/Estatístico, Simulação com } \\
\text { traçado de raios } \\
\end{array}$ \\
\hline Escolano et al. & 2013 & $\begin{array}{l}\text { A Diffusion Equation Model for Investigations on } \\
\text { Acoustics in Coupled-Volume Systems }\end{array}$ & Área de Acoplamento & $\begin{array}{l}\text { Medição em Escala, Modelo } \\
\text { Matemático/Estatístico }\end{array}$ \\
\hline Xiang et al. & 2013 & $\begin{array}{l}\text { Investigation on the Effect of Aperture Sizes and } \\
\text { Receiver Positions in Coupled Rooms }\end{array}$ & Área de Acoplamento & $\begin{array}{l}\text { Medição em Escala, Modelo } \\
\text { Matemático/Estatístico }\end{array}$ \\
\hline Luizard e Katz & 2014 & $\begin{array}{l}\text { Investigation of the Effective Aperture Area of Sliding } \\
\text { and Hinged Doors between Coupled Spaces }\end{array}$ & Área de Acoplamento & $\begin{array}{l}\text { Medição em Escala, Modelo } \\
\text { Matemático/Estatístico }\end{array}$ \\
\hline Garai et al. & 2015 & $\begin{array}{l}\text { Acoustic Measurements in Eleven Italian Opera } \\
\text { Houses: Correlations between Room Criteria and } \\
\text { Considerations on the Local Evolution of a Typology }\end{array}$ & Razão de Volumes & Medição \\
\hline $\begin{array}{l}\text { Luizard, Katz e } \\
\text { Guastavino }\end{array}$ & 2015 & $\begin{array}{l}\text { Perceptual Thresholds for Realistic Double-Slope } \\
\text { Decay Reverberation in Large Coupled Spaces }\end{array}$ & Área de Acoplamento & Avaliação Subjetiva \\
\hline Martellotta & 2016 & $\begin{array}{l}\text { Understanding the Acoustics of Papal Basilicas in } \\
\text { Rome by Means of a Coupled-Volumes Approach }\end{array}$ & Razão de Volumes & Medição \\
\hline Jeong e Joo & 2017 & $\begin{array}{l}\text { Prediction of Reverberance in Rooms with Simulated } \\
\text { Non-Single-Exponential Sound Decays }\end{array}$ & Área de Acoplamento & $\begin{array}{c}\text { Simulação com traçado de raios, } \\
\text { Avaliação Subjetiva }\end{array}$ \\
\hline
\end{tabular}

Fonte: Os autores

diferentes, sendo uma das salas mais reverberante que a outra. Para que haja duplo decaimento, a sala a ser acoplada pode ter maior ou menor tempo de reverberação, dependendo da posição relativa entre fonte e receptor. O tempo de reverberação é diretamente proporcional ao volume e inversamente proporcional à absorção equivalente do ambiente. Duas salas revestidas com mesmo material terão tempos de reverberação diferentes caso seus volumes sejam diferentes. Duas salas de mesmo volume terão tempos de reverberação diferentes caso os materiais que revestem as paredes de uma das salas sejam mais absorventes e os da outra sala mais reflexivos. A área de abertura entre as salas também influencia o comportamento do decaimento de energia 
sonora. Quanto maior a abertura de acoplamento entre as salas, maior é a quantidade de energia sonora que transita entre elas. Os tipos de curva de decaimento de energia que podem ocorrer em ambientes acoplados podem ser vistos no gráfico da Figura 5.

Figura 5: Tipo de curvas de decaimento sonoro em salas acopladas; (a) curva com decaimento de energia exponencial; (b) curva com decaimento de energia não exponencial com decaimento inicial menor que o decaimento final; (c) curva com decaimento de energia não exponencial com decaimento inicial maior que 0 decaimento final

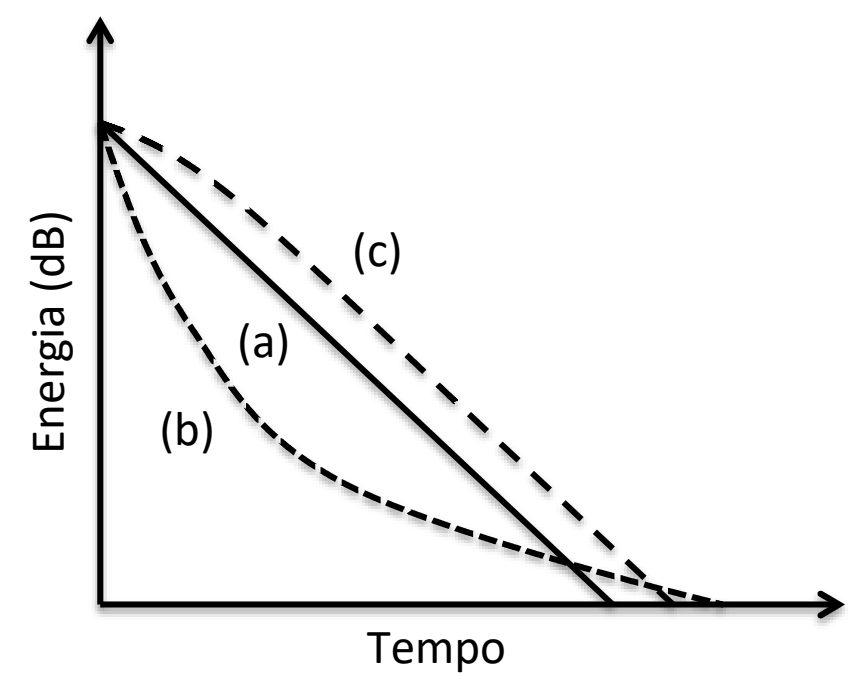

Fonte: Os autores

A curva (a) da Figura 5 mostra um decaimento considerado exponencial, típico de salas sem acoplamento. Em salas acusticamente acopladas, o decaimento pode ser exponencial caso fonte e receptor estejam na sala mais reverberante ou se a fonte estiver na sala mais reverberante e o receptor na menos reverberante. A curva (b) da Figura 5 mostra uma curva de decaimento de energia não exponencial onde $o$ decaimento inicial é menor que o decaimento final. Este decaimento acontece quando fonte e receptor estão na sala menos reverberante. Eyring (1931) encontrou ainda um terceiro tipo de curva de decaimento de energia não exponencial como a curva (c) mas a considerou praticamente semelhante à curva de decaimento exponencial se forem desconsiderados os primeiros decibels $(\mathrm{dB})$ de decaimento de energia. Este tipo de curva também é considerado como uma curva de decaimento de energia não exponencial, onde o tempo inicial de decaimento é maior que o tempo final de decaimento.

A curva (c) da Figura 5 pode ser observada quando a fonte está na sala com menor tempo de reverberação e o receptor na sala como maior tempo de reverberação. Entretanto, a diferença entre o tempo de reverberação entre as salas não pode ser muito grande. Os materiais que revestem ambas as salas devem ser reflexivos, ou seja, os volumes das salas devem ser diferentes.

A curva (b) da Figura 5 é o tipo de curva de decaimento sonoro encontrado em salas de concerto com câmaras reverberantes acopladas com a finalidade de proporcionar variabilidade acústica, já que proporcionaria as sensações de reverberância e clareza (ERMANN; JOHNSON, 2005).

As características arquitetônicas, do ponto de vista físico, que propiciam a formação de curvas com decaimento de energia sonora não exponencial são: a área de abertura entre as salas, as relações de volumes entre elas e os tipos de materiais que revestem as superfícies das salas (EYRING, 1931).

Ao longo dos anos, várias pesquisas se propuseram a estabelecer parâmetros acústicos que pudessem quantificar ou qualificar curvas de decaimento de energia não exponencial (BRADLEY; WANG, 2005, 2009, 2010; ERMANN, 2005a; ESCOLANO et al., 2013; JEONG; JOO, 2017). Estes parâmetros seriam uma maneira quantitativa de classificar estas curvas sem a necessidade de uma avaliação visual da curva de decaimento de energia. Parâmetros acústicos foram utilizados na comparação de resultados obtidos a partir do estudo da variação sistemática de determinadas características arquitetônicas. São eles a constante de acoplamento $\mathrm{T}_{30} / \mathrm{T}_{15}$ (ERMANN, 2005a), a taxa de decaimento e diferença de nível $(\triangle \mathrm{dB})$ (BRADLEY; WANG, 2005), a constante LDT/EDT, onde LDT é o tempo final de decaimento sonoro calculado entre o intervalo de decaimento de energia de $-25 \mathrm{~dB}$ a $-35 \mathrm{~dB}$ (BRADLEY; WANG, 2009), a constante LDT/ $\mathrm{T}_{10}$ (BRADLEY; WANG, 2010), o parâmetro $\Delta \mathrm{L}$ ou diferença de nível utilizado para o cálculo da posição do ponto de deflexão da curva de decaimento sonoro no eixo y (ESCOLANO et al., 2013) e o parâmetro $\mathrm{T}_{\mathrm{w}}$ que é a relação entre $-5 \mathrm{~dB}$ e $-35 \mathrm{~dB}$ do decaimento de energia sonora divididos em três partes iguais de $10 \mathrm{~dB}$ do decaimento de energia (JEONG; JOO, 2017).

O ponto de deflexão da curva, ou bending point pode ser considerado como o ponto mais próximo na curva de decaimento proveniente da intersecção das regressões lineares dos decaimentos iniciais e finais de uma curva de decaimento não exponencial e pode ser visto no gráfico da Figura 6 (LUIZARD; KATZ, 2014).

Um parâmetro arquitetônico é uma relação entre uma determinada característica arquitetônica entre as salas que estão acusticamente acopladas. Com a finalidade de permitir uma comparação direta entre estudos, foram propostos três parâmetros arquitetônicos relacionados às três características arquitetônicas que propiciam a formação de curvas de decaimento sonoro não 
exponencial em salas acopladas. São eles a Área de Acoplamento, Razão de Volumes e Razão de Absorção (BRADLEY; WANG, 2010). A Área de Acoplamento é a razão entre a área de abertura de acoplamento pela área total da sala principal, multiplicado por 100 e dado em porcentagem. A Razão de Volumes é a razão entre o volume secundário e o volume da sala principal multiplicado por 100 e dado em porcentagem. A Razão de Absorção é a razão entre a média da absorção equivalente da sala acoplada e a média da absorção equivalente da sala principal, calculada em função de banda de frequência.

Figura 6: Localização do ponto de deflexão da curva

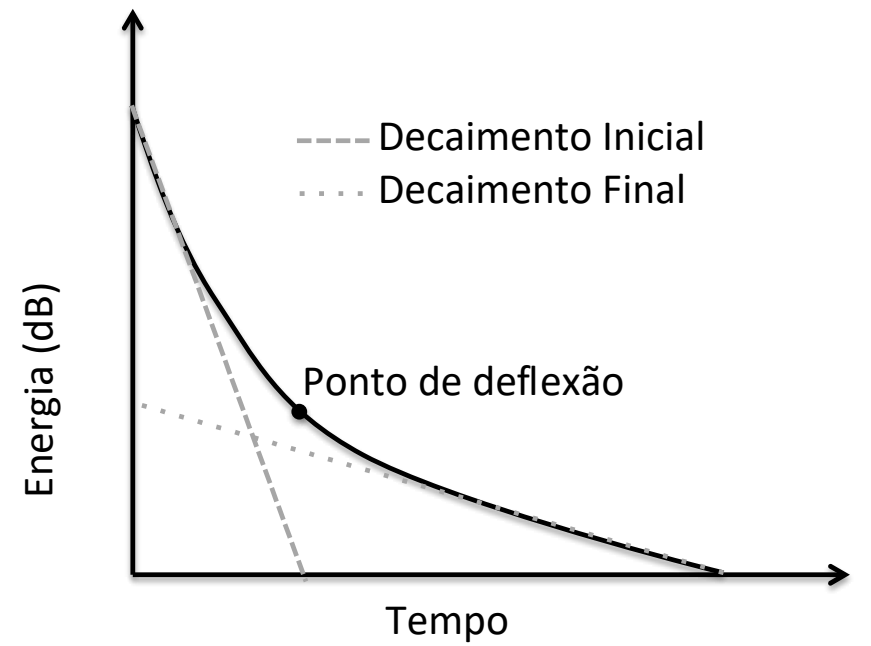

Fonte: Os autores

Várias pesquisas buscaram comparar resultados obtidos através de medições in loco ou em escala do decaimento de energia sonora com predições baseadas em modelos matemáticos ou resultados obtidos em simulação computacional. De maneira generalizada, tanto os resultados obtidos por modelos matemáticos como os resultados simulados do decaimento de energia obtiveram boa correlação com os resultados obtidos em medição (ANDERSON; BRATOS-ANDERSON, 2000; BRADLEY; WANG, 2005, 2006, 2007，2009，2010; ERMANN, 2005a, b, 2007; ERMANN; JOHNSON, 2005; ESCOLANO et al., 2013; EYRING, 1931; JEONG; JOO, 2017; LUIZARD; KATZ, 2014; MARTELLOTTA, 2009; MEISSNER, 2009; PU; QIU; WANG, 2011; XIANG et al., 2013).

Outras pesquisas buscaram realizar avaliações subjetivas de percepção da curva de decaimento de energia que pudessem ser relacionadas com os parâmetros propostos ou com as sensações de reverberância e clareza (BRADLEY; WANG, 2005; ERMANN, 2007; JEONG; JOO, 2017; LUIZARD; KATZ; GUASTAVINO, 2015). Por último, algumas pesquisas buscaram explicar o desempenho acústico do decaimento de energia de teatros e igrejas, obtidos por meio de medições acústicas, aplicando a teoria de espaços acoplados (ANDERSON; BRATOS-ANDERSON, 2000; GARAI et al., 2015; MARTELLOTTA, 2009, 2016).

Em resumo, são apresentados os principais resultados encontrados para cada um dos três parâmetros arquitetônicos propostos.

\section{Área de Acoplamento}

Os resultados encontrados sobre área de acoplamento são todos relacionados à situação típica de salas de concerto acopladas a uma câmara reverberante sendo que fonte e receptor se encontram juntos na sala com menor reverberação.

A área de acoplamento entre duas salas acopladas é um dos parâmetros arquitetônicos que tem grande influência na produção de curvas de decaimento sonoro não exponencial especialmente quando há uma diferença grande no tempo de reverberação entre as duas salas (ERMANN; JOHNSON, 2005). Pequenas variações na área de acoplamento provocam grandes mudanças no tempo total de decaimento (ERMANN, 2005a). Os maiores valores dos parâmetros que comparam partes distintas do decaimento como as constantes $\mathrm{T}_{30} / \mathrm{T}_{15}$, LDT/EDT e LDT/T 10 são encontrados em pequenas áreas de acoplamento, em torno de $1 \%$ a $3 \%$. Isto indica que para pequenas áreas de acoplamento, a curva de decaimento de energia apresenta a maior característica de duplo decaimento (BRADLEY; WANG, 2005, 2006, 2009, 2010; ERMANN, 2005a). Conforme as áreas de acoplamento aumentam, entre $5 \%$ a $10 \%$, a curva de decaimento de energia tende a um decaimento exponencial (BRADLEY; WANG, 2005, 2006, 2009, 2010; ERMANN, 2005a). A posição do ponto de deflexão da curva de decaimento de energia também muda conforme a área de acoplamento varia. Quanto maior é a área de acoplamento, maior é o valor da localização do ponto de deflexão da curva de decaimento em relação ao eixo de energia sonora (eixo y) (ESCOLANO et al., 2013; XIANG et al., 2013). Em salas acopladas, a sensação de reverberância percebida é maior quanto maior for a área de acoplamento (BRADLEY; WANG, 2005; JEONG; JOO, 2017). Luizard, Katz e Guastavino (2015) propõem que, para uma mudança na sensação de reverberação, a menor variação na área de acoplamento deve ser de $10 \%$ de abertura. A maneira com que as aberturas entre as salas são feitas também é importante. Portas deslizantes propiciam uma mudança linear no valor da localização do ponto de deflexão da curva de decaimento em relação ao eixo de energia sonora. Em portas de abrir, o ângulo de abertura modifica a área de acoplamento. Pequenos 
ângulos de abertura proporcionam maior variação na posição do ponto de deflexão em relação a ângulos maiores de abertura (LUIZARD; KATZ, 2014). Ainda em relação à percepção, há indícios que o duplo decaimento da curva de energia seja melhor percebido em situações onde há um acorde final e consegue-se ouvir todo o decaimento sonoro. Em situações onde a música é executada continuamente, a percepção do duplo decaimento é mais difícil (ERMANN, 2007). Há indícios de preferência dos ouvintes em salas de concerto por curvas com decaimento sonoro exponencial em relação ao decaimento sonoro não exponencial (BRADLEY; WANG, 2010). Em estudo específico, analisando baixas frequências, a área de acoplamento apresentou pouca variação nas frequências naturais da sala com exceção das frequências fundamentais de ressonância, mostrando que o fenômeno do duplo decaimento varia em função de frequência (MEISSNER, 2009).

\section{Razão de Volumes}

Apesar do grande interesse no estudo de salas acopladas com espaços reverberantes estar relacionado a salas de concerto, edificações como igrejas e catedrais, são ambientes onde também se encontra o acoplamento sonoro. Em igrejas e catedrais, o acoplamento entre os diversos espaços como altar, coro, nave principal, corredores laterais e capelas colaterais, propicia a formação de curvas de decaimento sonoro não exponencial. Como nestes espaços o revestimento das paredes é feito normalmente com material reflexivo e as áreas de acoplamento são consideravelmente grandes, a diferença entre os volumes acoplados é a maior responsável por proporcionar curvas com decaimento de energia não exponencial (ANDERSON; BRATOSANDERSON, 2000; MARTELLOTTA, 2009). Em várias catedrais, observou-se que quando fonte e receptor estão em um espaço de volume menor, como a área do coro, que é acusticamente acoplada a um espaço de maior volume como a nave, há a ocorrência de curva de decaimento de energia não exponencial com decaimento inicial menor que o decaimento final (ANDERSON; BRATOS-ANDERSON, 2000; MARTELLOTTA, 2009, 2016). Observou-se também que quando a fonte sonora se encontra em um espaço de menor volume e o receptor em um espaço de maior volume, a curva de decaimento também apresenta decaimento não exponencial, entretanto, o decaimento inicial é maior que o decaimento final. (ANDERSON; BRATOSANDERSON, 2000).

No caso de salas de concertos com câmaras acopladas, Bradley e Wang (2005) observaram que a constante de acoplamento $T_{30} / T_{15}$ apresenta valores maiores à medida que o volume da sala acoplada aumenta. Entretanto, para que isso aconteça, a absorção equivalente da sala acoplada deve ser consideravelmente baixa. Em relação à sensação de reverberância, quanto maior a razão de volumes, maior a sensação de reverberância (BRADLEY; WANG, 2005). Garai et al. (2015) mostraram que as caixas cênicas em vários teatros de ópera italianos podem ser acusticamente acopladas à área de audiência, proporcionando curvas com decaimento de energia não exponencial.

\section{Razão de Absorção}

As propriedades acústicas dos materiais que revestem as salas influenciam significativamente a curva de decaimento de energia. Eyring (1931) propôs que curvas com decaimento de energia não exponencial podem ser obtidas apenas quando o coeficiente de absorção médio da sala acoplada é menor que 0,07 . Isto significa que a sala acoplada deve ser bastante reverberante. Quanto mais reverberante a sala acoplada, ou seja, menor o valor da razão de absorção entre as salas, maiores os valores da constante de acoplamento $\mathrm{T}_{30} / \mathrm{T}_{15}$ e $\mathrm{LDT} / \mathrm{T}_{10}$ (BRADLEY; WANG, 2005, 2010; ERMANN, 2005b; ERMANN; JOHNSON, 2005). Ermann e Johnson (2005) mostraram que os maiores valores da constante de acoplamento $\mathrm{T}_{30} / \mathrm{T}_{15}$ foram obtidos com materiais de revestimento da sala acoplada em que o coeficiente de absorção era menor que 0,02 . Quanto maior o valor da razão de absorção, maior é a tendência da curva de decaimento de energia ser exponencial (BRADLEY; WANG, 2010; ERMANN; JOHNSON, 2005).

Um resumo dos valores encontrados nos artigos selecionados para a revisão Sistemática da Literatura dos três parâmetros arquitetônicos pode ser visto na Tabela 1 .

Tabela 1: Valores encontrados na literatura nos estudos dos parâmetros arquitetônicos: Área de Acoplamento, Razão de Volumes e Razão de Absorção

\begin{tabular}{cc} 
Parâmetros arquitetônicos & $\begin{array}{c}\text { Valores encontrados nos } \\
\text { estudos }\end{array}$ \\
\hline Área de Acoplamento & $0,1 \%$ a $12,9 \%$ \\
\hline Razão de Volumes & $20 \%$ a $50 \%$ \\
\hline Razão de Absorção & 0,03 a 0,16 \\
\hline
\end{tabular}

Fonte: Os Autores

Esta faixa de valores encontrada pode servir como uma referência inicial para projetos arquitetônicos que necessitem da acústica variável com câmaras reverberantes acopladas.

\section{Conclusões}

O estudo feito aplicando a Revisão Sistemática da Literatura pôde trazer um panorama atual no conhecimento a respeito das características arquitetônicas de ambientes que influenciam o decaimento de energia não exponencial entre salas acopladas. Pôde-se constatar o aumento do interesse pelo assunto a partir do ano de 
2000 associado à inauguração de diversas salas de concerto com variação acústica obtidas com o acoplamento de salas reverberantes. O desempenho acústico de igrejas e catedrais também vem sendo explicado devido ao acoplamento entre seus diversos espaços. O estudo mostrou que a área da psicoacústica é a menos pesquisada e pode ser explorada em novas pesquisas. Questões relacionadas à razão de absorção e razão de volume também podem ser objeto de novas pesquisas já que apresentam menos estudos que a área de acoplamento. Teatros com caixa cênica podem ser objetos de estudo na área e poderão trazer diretivas para a variação acústica utilizando-se da caixa cênica como espaço acoplado ao teatro.

\section{Agradecimentos}

Os autores gostariam de agradecer Ítalo Guedes Montalvão, Rafaella Estevão da Rocha e Fernanda Almeida Machado pelas considerações e auxílio à compreensão do método da revisão sistemática da literatura. Agradecem também à CAPES, pelo apoio financeiro desta pesquisa.

\section{Referências}

ANDERSON, J. S.; BRATOS-ANDERSON, M. Acoustic coupling effects in St Paul's Cathedral, London. Journal of Sound and Vibration, v. 236, n. 2, p. 209-225, 2000. doi: https://doi.org/10.1006/jsvi.1999.2988

ARTEC. Concert Theatres. Disponível em: <http://www.artecconsultants.com/03_projects/venue_types/concert_theatres.html>. Acesso em: 21 ago. 2017.

BRADLEY, D. T.; WANG, L. M. Comparison of measured and computer-modeled objective parameters for an existing coupled volume concert hall. Building Acoustics, v. 14, n. 2, p. 79-90, 2007. doi: https://doi.org/10.1260/135101007781448028

BRADLEY, D. T.; WANG, L. M. Optimum absorption and aperture parameters for realistic coupled volume spaces determined from computational analysis and subjective testing results. Journal of the Acoustical Society of America, v. 127, n. 1, p. 223-232, 2010. doi: https://doi.org/10.1121/1.3268604

BRADLEY, D. T.; WANG, L. M. Quantifying the double slope effect in coupled volume room systems. Building Acoustics, v. 16, n. 2, p. 105-123, 2009. doi: https://doi.org/10.1260/135101009788913275

BRADLEY, D. T.; WANG, L. M. Room acoustics in coupled volume spaces. In: 2006 ARCHITECTURAL ENGINEERING NATIONAL CONFERENCE. Anais. Omaha, NE, United states, 2006. p. 24-29.

BRADLEY, D. T.; WANG, L. M. The effects of simple coupled volume geometry on the objective and subjective results from nonexponential decay. Journal of the Acoustical Society of America, v. 118, n. 3, p. 1480-1490, 2005. doi:https://doi.org/10.1121/1.1984892

ERMANN, M. Coupled volumes: Aperture size and the double-sloped decay of concert halls. Building Acoustics, v. 12, n. 1, p. 114, 2005a. doi: https://doi.org/10.1260/1351010053499252

ERMANN, M. Coupled volumes: Secondary room reverberance and the double-sloped decay of concert halls. Building Acoustics, v. 12, n. 3, p. 165-174, 2005b. doi: https://doi.org/10.1260/135101005774353069

ERMANN, M. Double Sloped Decay: Subjective Listening Test to Determine Perceptibility and Preference. Building Acoustics, v. 14, n. 2, p. 91-107, 2007. doi: https://doi.org/10.1260/135101007781448055

ERMANN, M.; JOHNSON, M. Exposure and materiality of the secondary room and its impact on the impulse response of coupledvolume concert halls. Journal of Sound and Vibration, v. 284, n. 3-5, p. 915-931, 2005. doi:https://doi.org/10.1016/j.jsv.2004.07.030

ESCOLANO, J. et al. A diffusion equation model for investigations on acoustics in coupled-volume systems. In: MEETINGS ON ACOUSTICS. Proceedings... Montreal, QC, Canada, 2013.

EYRING, C. F. Reverberation time measurements in coupled rooms. Journal of the Acoustical Society of America, v. 3, n. 2A, p. 181-206, 1931. doi: https://doi.org/10.1121/1.1915555 
GARAI, M. et al. Acoustic measurements in eleven Italian opera houses: Correlations between room criteria and considerations on the local evolution of a typology. Building and Environment, v. 94, Part 2, p. 900-912, 2015.

doi:https://doi.org/10.1016/j.buildenv.2015.07.026

JEONG, D.; JOO, H. Prediction of reverberance in rooms with simulated non-single-exponential sound decays. Applied Acoustics, v. 125, p. 136-146, 2017. doi: https://doi.org/10.1016/j.apacoust.2017.04.018

JOHNSON, R.; KAHLE, E.; ESSERT, R. Variable coupled cubage for music performance. In: MUSIC AND CONCERT HALL ACOUSTICS CONFERENCE. Anais... Japan, 1995.

KITCHENHAM, B. Procedures for Performing Systematic Reviews, 2004. 28 p. (Keele University Technical Report TR/SE0401).

LUIZARD, P.; KATZ, B. F. G. Investigation of the effective aperture area of sliding and hinged doors between coupled spaces. Journal of the Acoustical Society of America, v. 136, n. 2, p. EL135-EL141, 2014. doi: https://doi.org/10.1121/1.4890202

LUIZARD, P.; KATZ, B. F. G.; GUASTAVINO, C. Perceptual thresholds for realistic double-slope decay reverberation in large coupled spaces. Journal of the Acoustical Society of America, v. 137, n. 1, p. 75-84, 2015.

MARTELLOTTA, F. Identifying acoustical coupling by measurements and prediction-models for St. Peter's Basilica in Rome. Journal of the Acoustical Society of America, v. 126, n. 3, p. 1175-1186, 2009. doi: https://doi.org/10.1121/1.4904515

MARTELLOTTA, F. Understanding the acoustics of Papal Basilicas in Rome by means of a coupled-volumes approach. Journal of Sound and Vibration, v. 382, p. 413-427, 2016. doi: https://doi.org/10.1016/j.jsv.2016.07.007

MEISSNER, M. Computer modelling of coupled spaces: Variations of eigenmodes frequency due to a change in coupling area. Archives of Acoustics, v. 34, n. 2, p. 157-168, 2009. Disponível em <http://acoustics.ippt.gov.pl/index.php/aa/article/view/572>. Acesso em: 22 de Jan. de 2018.

PU, H.; QIU, X.; WANG, J. Different sound decay patterns and energy feedback in coupled volumes. Journal of the Acoustical Society of America, v. 129, n. 4, p. 1972-1980, 2011. doi: https://doi.org/10.1121/1.3553223

SABINE, W. C. Collected papers on acoustics. London, U.K.: Cambridge : Harvard University Press, 1922.

XIANG, N. et al. Investigation on the effect of aperture sizes and receiver positions in coupled rooms. Journal of the Acoustical Society of America, v. 133, n. 6, p. 3975-3985, 2013. doi: https://doi.org/10.1121/1.4802740

\author{
${ }^{1}$ Alexandre Virginelli Maiorino \\ Músico. Mestre em Engenharia Civil. Rua São Salvador, 220, Torre 4 Apto. 183, Campinas, SP, Brasil, CEP 13076-540 \\ ${ }^{2}$ Stelamaris Rolla Bertoli \\ Física. Pós-Doutorado. Av. Albert Einstein, 951, Caixa Postal 6021, Campinas, SP, Brasil, CEP 13083970
}

